\title{
Smoking in pregnancy: some notes on the statistical controversy
}

\author{
HAR VEY GOLDSTEIN* \\ From the National Children's Bureau, 8 Wakley Street, London
}

SUMMARY The statistical evidence for a relationship between pregnancy smoking, birthweight, and perinatal mortality is critically examined. Some apparent discrepancies between and within different studies are resolved.

The debate over the relationship between maternal smoking during pregnancy and subsequent damage to the fetus has centred around two issues. The first issue is similar to one often encountered in other debates on smoking, namely, whether a statistical association can be interpreted causally. The second issue is concerned with the reliability of the statistical results themselves.

Unlike most other links between smoking and disease, the case of pregnancy smoking can be submitted to designed experimentation to give a rigorous test of the causal hypothesis. Such an experiment would consist of a group of pregnant women subjected to intensive anti-smoking advice and compared, in terms of the status of their offspring, with a control group not so subjected. The first such experiment which has been adequately designed, although inconclusive in its results, has now been reported (Donovan, 1977) and the purpose of the current paper is to provide a background and summary of previous evidence and to comment on it scientifically.

It has often appeared that the important debate is about the interpretation of causation and not about the statistical findings themselves (Nature, 1973). In fact, however, rival causal interpretations of the statistical associations do not account for most of the controversy. They have certainly been important motivations inspiring different research workers, but the disputes themselves have centred largely on the comparison and validity of the statistical analyses. Moreover, the demonstration of a statistical association is only one stage in the whole scientific process, and if one accepts the views of Popper (1973), the idea of a direct 'causal' link between smoking in pregnancy and fetal outcome is a rather better theory than, say, the 'constitutional'

*Present address: Institute of Education, University of London, 20 Bedford Way, London WC1H OAL or 'genetic' theories, because it is more open to falsification. I shall describe some unsuccessful attempts to falsify the first theory, whereas I know of no published attempts to falsify the other two types of theory. It is precisely the all-embracing statement of the other two theories that makes them scientifically unattractive, and also, incidentally, drives their proponents into attempting statistical falsifications of the first theory.

There are now many papers that confirm the finding of Simpson (1957) that babies born to mothers who smoke during pregnancy are, on average, about $200 \mathrm{~g}$ lighter than those born to non-smokers. There are fewer papers on the relationship between smoking and perinatal mortality and they can be divided into those which detect a sizeable association and those which do not. There are few articles which analyse the relationship between smoking in pregnancy and subsequent child development.

\section{Birthweight}

Several studies have demonstrated a dose-effect relationship between mean birthweight and the numbers of cigarettes smoked during pregnancy (Butler et al., 1972; Niswander and Gordon, 1972). They show a large birthweight reduction in moving from non-smokers to those mothers who smoke up to about 15 cigarettes a day but there is a smaller decrease beyond this amount. Since most studies, however, only classify the mothers into smokers and non-smokers this dichotomy will be used in the following discussions.

The proportion of the population who smoke differs quite considerably from one study to another (Table 1) and hence we would expect the average number of cigarettes smoked to differ also, and consequently that the differences between 
Table 1 Proportion of mothers who were smokers, proportion of births $\leqslant 2500 \mathrm{~g}$ in smokers and non-smokers, ratio of mortality in smokers to that in non-smokers in six large samples from white populations

\begin{tabular}{|c|c|c|c|c|c|c|}
\hline \multirow[b]{2}{*}{ Study } & \multirow[b]{2}{*}{ Year } & \multirow{2}{*}{$\begin{array}{l}\text { Sample } \\
\text { size } \\
\text { number }\end{array}$} & \multirow[b]{2}{*}{$\underset{\%}{\text { Smokers }}$} & \multicolumn{2}{|c|}{ Low birthweight } & \multirow{2}{*}{$\begin{array}{l}\text { Mortality ratio } \\
\text { smokers/non- } \\
\text { smokers }\end{array}$} \\
\hline & & & & $\underset{\%}{\text { Smokers }}$ & $\begin{array}{l}\text { Non- } \\
\text { smokers } \\
\%\end{array}$ & \\
\hline $\begin{array}{l}\text { Rantakallio } \\
\text { Yerushalmy } \\
\text { Niswander and Gordon } \\
\text { Ontario Canada* } \\
\text { Butler et al. } \\
\text { Comstock et al. }\end{array}$ & $\begin{array}{l}1969 \\
1971 \\
1972 \\
1967 \\
1972 \\
1971\end{array}$ & $\begin{array}{r}11700 \\
9800 \\
19000 \\
51500 \\
223300 \\
12500\end{array}$ & $\begin{array}{l}21 \\
38 \\
54 \\
43 \\
32 \\
37\end{array}$ & $\begin{array}{l}6 \cdot 1 \\
6 \cdot 4 \\
9 \cdot 5 \\
8 \cdot 9 \\
9 \cdot 3 \\
11 \cdot 1\end{array}$ & $\begin{array}{l}3 \cdot 5 \\
3 \cdot 2 \\
4 \cdot 3 \\
4 \cdot 5 \\
5 \cdot 4 \\
5 \cdot 9\end{array}$ & $\begin{array}{l}1.01 \text { (PNM) } \\
1.03 \text { (NNM) } \\
1.12 \text { (PNM) } \\
1.27 \text { (PNM) } \\
1.28 \text { (PNM) } \\
1.40 \text { (NNM) }\end{array}$ \\
\hline
\end{tabular}

*The Ontario Study included babies born dead before 28 weeks' gestation, these rates have been adjusted to conform to the ICD 1967 definitions -7 of perinatal mortality. This has little effect on the mortality ratio.

PNM: The mortality ratio is based upon perinatal mortality rates.

NNM: The mortality ratio is based upon neonatal mortality rates.

average birthweights of children of smokers and non-smokers will change. In fact the range of difference in birthweight is quite small for most studies, about $160-200 \mathrm{~g}$. There also seems to be general agreement (Comstock et al., 1971) that the birthweight distribution for children of mothers who smoke is almost identical with that for non-smokers except for a shift in the mean value. Figure 1 illustrates this shift and also the likely consequence that this will have for the low birthweight babies when this is defined as those of $2500 \mathrm{~g}$ and under; paradoxically although mothers who smoke will have a greater proportion of low birthweight babies, the mean birthweight of the smokers' babies in this group will probably be higher than that of the mean weight of the non-smokers' babies. Although this will not necessarily be true for all populations, the difference in the mean birthweight of low birthweight infants of smoking and non-smoking mothers will be considerably narrower than the difference in mean birthweights of all infants. In the British Perinatal Mortality Survey, for example, low birthweight babies of mothers smoking 10 or more cigarettes a day have a mean birthweight of $2072 \mathrm{~g}$, those smoking 1-9 a day have a mean birthweight of $2011 \mathrm{~g}$, and nonsmokers have a mean birthweight of $2062 \mathrm{~g}$. In fact, if the birthweight distributions are exactly gaussian with equal variances, then Fig. 1 represents what in fact happens for these distributions. Thus in terms of mean birthweight, the low birthweight babies of smokers do not suffer a disadvantage, a fact which is of some technical interest but little practical relevance. It will be referred to again when discussing the controversy over perinatal mortality rates.

Those who claim that the statistical association is spurious because it is merely a reflection of a deeper underlying cause hold that there are certain kinds of mothers who both smoke and happen to

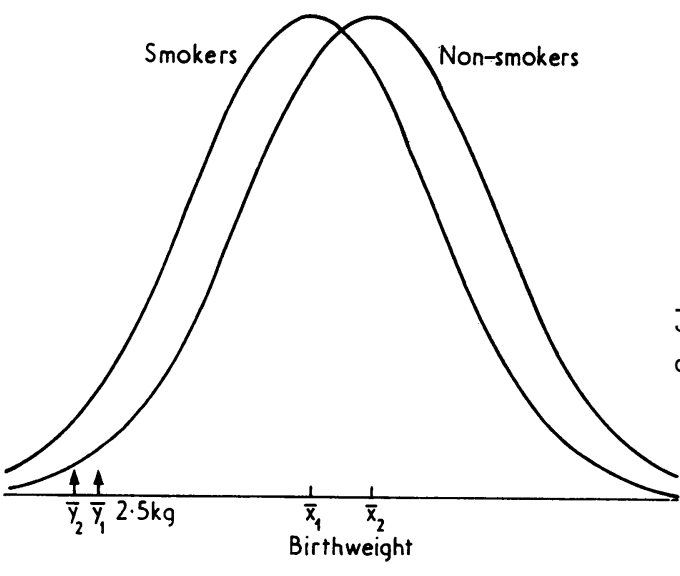

Fig. 1 Birthweight distribution for babies of mothers who smoke and of mothers who do not. (Not to scale.) $\overline{\mathrm{x}}_{1}=$ mean birthweight for babies of smokers.

$\overline{\mathbf{x}}_{2}=$ mean birthweight for babies of non-smokers.

$\underline{\bar{y}}_{1}=$ mean birthweight for smokers for births $\leqslant 2 \cdot 5 \mathrm{~kg}$.

$\bar{y}_{2}=$ mean birthweight for non-smokers for births $\leqslant 2 \cdot 5 \mathrm{~kg}$.

have lower than average birthweight babies, and that the real task is to discover what kinds of mothers these are. Although it is not possible to dispose of this claim by citing evidence only from epidemiological surveys, it is possible to narrow the range of plausible explanations using such evidence. For example, several studies have made allowance for possible 'mediatory' factors such as social class, maternal age, and parity. Within the categories of such factors, however, the difference between smokers and non-smokers persists virtually unchanged (Butler et al., 1972). If there is a mediatory factor it seems that it is likely to be of a different kind, possibly a genetic one.

Another test of the causal explanation is to study those women who gave up smoking in the early 
part of pregnancy. If smoking acts as a causal agent during pregnancy, then these women ought to have babies with an average birthweight between that of the babies of smokers and non-smokers. In fact, those who stated that they had given up smoking by the fourth month of pregnancy had babies whose birthweight distribution was virtually indistinguishable from that of non-smokers; (in the British Perinatal Mortality Survey the respective average birthweights are $3367 \mathrm{~g}$ and $3350 \mathrm{~g}$ ). It is, of course, possible to argue that the woman who gives up smoking during pregnancy is really a 'non-smoking' type. The point, however, is that this represents another failure to falsify the causal hypothesis. In addition it suggests that the second half of pregnancy may be the vulnerable period but this should be interpreted cautiously because such information about changes in smoking habits is usually obtained retrospectively and may not be reliable concerning timing.

We could test further the causal hypothesis by comparing babies born to those women who gave up smoking after delivery with babies of mothers who were non-smokers. This was attempted by Yerushalmy (1972) who found a small but statistically non-significant increase in the proportion of low birthweight babies among the former group. He also found that the proportion of low birthweight babies born to mothers under 25 years old who had their first baby before they started to smoke was significantly higher than among corresponding non-smokers. On the face of it this seems to provide evidence against the causal hypothesis, but on closer examination the validity of these findings turns out to be questionable.

Firstly, the data on smoking habits were obtained retrospectively going back over a number of years, with the possibility that many of the mothers who were classified as becoming smokers only after their babies' birth would in fact have been smoking during the pregnancy. Secondly, the mothers who smoked not only had their first baby before they were 25 years old, but actually started to smoke before that age, so that they would tend to have had their first babies at younger ages than those mothers who had never smoked under 25 years. In fact, they were on average about two years younger in Yerushalmy's study (personal communication). Moreover, several studies, including that by Yerushalmy, have shown that the proportion of low birthweight babies born to mothers under 20 years is about $20 \%$ to $25 \%$ higher than for mothers aged between 20 and 24 years. Hence a proper age standardisation would be necessary before drawing conclusions. Until a large-scale prospective study following young women through several pregnancies can be carried out, this test of the causal hypothesis cannot be made. It appears, therefore, that all attempts to falsify the causal hypothesis concerning the effect of smoking on birthweight have so far proved failures, thus serving to strengthen our belief in it.

\section{Perinatal mortality}

Table 2 sets out the chances, for different sample sizes, of detecting a statistically significant difference at the $5 \%$ level between the perinatal mortality rates of infants born to smokers and non-smokers. This table demonstrates that it is only the very largest samples which are likely to give a clear indication of any difference.

Table 2 Sample sizes necessary to achieve a given chance of obtaining a statistically significant difference (at the $5 \%$ level) in perinatal mortality rates of smokers and non-smokers

\begin{tabular}{lc}
\hline $\begin{array}{l}\text { Probability of a } \\
\text { significant result }\end{array}$ & $\begin{array}{l}\text { Sample size } \\
\text { (nearest 1000) }\end{array}$ \\
\hline 0.5 & 9000 \\
0.6 & 11000 \\
0.7 & 14000 \\
0.8 & 17000 \\
0.9 & 23000 \\
0.95 & 29000 \\
\hline
\end{tabular}

It is assumed that the mortality rates and proportions of smokers and non-smokers are those found in the British Perinatal Mortality Survey.

The mortality ratio is defined as the ratio of the mortality rate found in infants of mothers who smoke to the rate found in those who are nonsmokers. This mortality ratio may be calculated either for the perinatal mortality or for the neonatal mortality according to the information available in a particular study. Butler et al. (1972) and Comstock et al. (1971) found it was possible to calculate both ratios and the difference was very small. The results for six studies are shown in Table 1 . The first three studies have low mortality ratios which do not give a statistically significant difference. But these three studies also have the lowest proportion of low-birthweight babies among nonsmokers, with a very close association between this low-birthweight rate and the mortality ratio.

This association provides one possible explanation for the differing mortality ratios. Figure 2 shows the relationship between perinatal mortality and birthweight in the British Perinatal Mortality Survey. It is clear that a reduction of about $200 \mathrm{~g}$ for a baby weighing $3500 \mathrm{~g}$ leads to less than a $10 \%$ increase in mortality risk, whereas the same reduction for a $2500 \mathrm{~g}$ baby results in about a $30 \%$ increase. Clearly therefore, the more low-birthweight 
babies there are in a population, the greater the increase in the mortality rate associated with the average decrease of about $200 \mathrm{~g}$ due to smoking. One important consequence of this explanation, if we assume a causal relationship, is that the greatest risk from smoking is to the mother who is already at 'high risk', who can expect a lower than average birthweight baby and who is poor, short, high parity, etc.

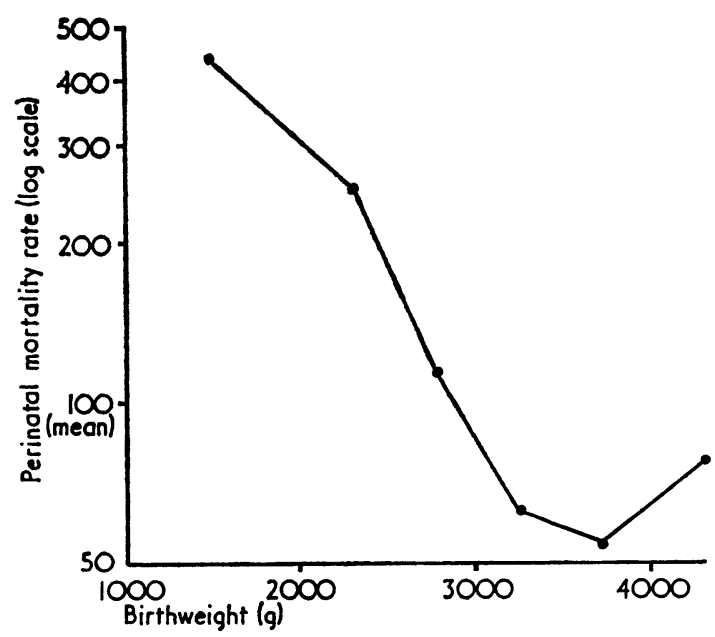

Fig. 2 Perinatal mortality rate by birthweight. (1958 British Perinatal Mortality Survey, mean=100.)

Professor Yerushalmy, who was one of the main opponents of the causal hypothesis, raised a further paradoxical finding which he claimed cast doubt on a causal link. He points out that in his own and other studies, the mortality among low birthweight babies of smokers is lower than among lowbirthweight babies of non-smokers. Yerushalmy (1972) failed to account for this in terms of downward shift in birthweights of smokers. Unfortunately, his claim that a 'shift' explanation is untenable is not justified, for reasons given in detail elsewhere (Goldstein, 1972). This gist of the argument, however, can be gleaned from Fig. 1, where as pointed out earlier, the low-birthweight babies of smokers tend to have a higher average birthweight than those of non-smokers. There is no reason to be surprised, therefore, if they manifest a lower mortality. Far from being 'paradoxical', such a finding is to be expected, and is not particularly relevant to the main issue.

As in the case of birthweight, the relationship between smoking and mortality persists after allowing for similar mediatory factors, and there is a similar dose-response relationship between perinatal mortality and number of cigarettes smoked. Also, those who had given up by the fourth $\mathbb{Q}$ month had a very similar rate $(31.6$ per 1000 births in the non-smokers and $32 \cdot 2$ per 1000 births in the smokers). As with birthweight, therefore, these failures to falsify the causal hypothesis lend it further strength.

\section{Subsequent child development}

Very few studies have followed-up large enough $\vec{\circ}$ samples of babies to compare adequately the development of those born to smokers with those ${ }_{\sigma}$ born to non-smokers. The surviving babies of the British Perinatal Mortality Survey have, however, $)$ been followed to the age of 11 years in the National $\omega$ Child Development Study, and small differences still persist at that age (Butler and Goldstein, 1973).

There is, for example, a $1.6 \mathrm{~cm}$ difference in height between children of heavy smokers (10 or more cigarettes a day) and non-smokers. Unlike birth- $\bar{z}$ weight, however, this difference is reduced by nearly $40 \%$ when account is taken of 'mediatory' factors $\frac{\partial}{\partial}$ such as social class, family size, and maternal $\overrightarrow{0}$ height. This suggests that the association may nof be wholly causal, and that when further mediatory factors are taken into account, they may explain the major part of this association. In any case, the difference at this age is small when compared with the average differences associated with social class and family size which are of the order of several $\triangle$ centimetres. The story is similar for educational $\overrightarrow{\overrightarrow{0}}$ attainment. With reading, for example, the difference 3 between children of heavy smokers and non-smokers is about nine months of reading age, which reduces to about four months after allowing for the same mediatory factors.

\section{Conclusions}

The main objections to the statistical case for a causal relationship between smoking in pregnancy 의 and birthweight and mortality do not bear much scrutiny. Apparent inconsistencies in comparisons of mortality rates have, in fact, straightforward interpretations in terms of the downward shift in the birthweight distribution among smokers. Various attempts to falsify the causal hypotheses have failed, leaving us with good reason for acting as if smoking really did cause a decrease in birthweight and an increased risk of perinatal mortality. On this assumption, it is estimated that in the perinatal period about 1500 babies die in Britain every year because their mothers smoke, out of a total of about 18000 deaths. In the United States of America about 4600 die out of a total of about 87000 deaths 
a year (United States Public Health Service, 1973.) Whatever is felt about the usefulness of health education propaganda, there are seen to be good reasons for attempting to dissuade pregnant women from smoking. If properly planned, with adequate controls, health education experiments can be mounted to determine not only whether women respond by changing their smoking habits, but also whether there is any appreciable effect on the pregnancy outcome. The apparent success or failure of such experiments may not only throw light on the causal hypothesis, but may also help to design efficient health education techniques.

My thanks are due to Michael Healy, Ken Fogelman, Maurice Backett, and Neville Butler for their comments and to the National Birthday Trust Fund for the use of some of the material. This work was supported by grants from the Department of Health and Social Security, the Department of Education and Science and the Social Science Research Council (UK).

Reprints from Harvey Goldstein, Department of Statistics and Computing, Institute of Education, 20 Bedford Way, London WC1H OAL.

\section{References}

Butler, N. R., and Goldstein, H. (1973). Smoking in pregnancy and subsequent child development. British Medical Journal, 4, 573-575.

Butler, N. R., Goldstein, H., and Ross, E. M. (1972). Cigarette smoking in pregnancy: its influence on birthweight and perinatal mortality. British Medical Journal, 2, 127-130.
Comstock, G. W., Shah, F. K., Meyer, B., and Abbey, H. (1971). Low birthweight and neonatal mortality rate related to maternal smoking and socioeconomic status. American Journal of Obstetrics and Gynecology, 111, 53-59.

Department of Health (1967). Supplement to the Second Report of the Perinatal Mortality Study. Ontario Department of Health: Canada.

Donovan, J. W. (1977). Randomised controlled trial of anti-smoking advice in pregnancy. British Journal of Preventive and Social Medicine, 31, 6-12.

Goldstein, H. (1972). Birthweight and the displacement hypothesis. An analysis of method. American Journal of Epidemiology, 95, 1-2.

Nature (1973). Editorial. Smoking, pregnancy and publicity. Nature, 245, 61.

Niswander, K. R., and Gordon, M. (1972). The Women and their Pregnancies. Saunders: Philadelphia.

Popper, K. R. (1973). Objective Knowledge, an Evolutionary Approach. Oxford University Press: London.

Rantakallio, P. (1969). Groups at risk in low birthweight infants and perinatal mortality. Acta paediatrica, Supplement 193:1 + (174 Ref.).

Simpson, W. J. (1957). A preliminary report of cigarette smoking and the incidence of prematurity. American Journal of Obstetrics and Gynecology, 73, 808-815.

United States Public Health Service (1973). The health consequences of smoking, chapter 4. A Report of the Surgeon General: 1973. US Department of Health, Education and Welfare: Washington.

Yerushalmy, J. (1971). The relationship of parents' cigarette smoking to outcome of pregnancyimplications as to the problem of inferring causation from observed associations. American Journal of Epidemiology, 93, 443-456.

Yerushalmy, J. (1972). Infants with low birthweight born before their mothers started to smoke cigarettes. American Journal of Obstetrics and Gynecology, 112, 227-284. 